\title{
Sustainability: A Path-breaking Idea, but Still Associated with Huge Challenges
}

\author{
Juergen Peter Kropp \\ Potsdam Institute for Climate Impact Research (PIK), Telegraphenberg A 31, 14473 Potsdam, Germany; \\ E-Mail: kropp@pik-potsdam.de
}

Submitted: 3 May 2013 | Published: 10 May 2013

Sustainability science is a young discipline that started emerging in the late 20th century, although Hans Carl von Carlowitz had already introduced ideas about sustainable management of forests in the early 18th century. In recent times, the Club of Rome report in 1972 and the Brundtland report in 1987 developed these concepts further, and subsequently the sustainability idea became prominent in political debates as well. In both reports it was recognized that growth would have certain limits and a different style of resource utilization was therefore necessary. However, despite numerous approaches dealing with sustainability, it is still an important issue.

Nowadays humanity increasingly interferes with natural systems on a planetary scale. This holds for many subsystems of the Earth including the climate, soil and water bodies, and marine systems. During the 20th century, rapid technological development and demographic pressure advanced to a degree that we caused radical and unintended changes in the Earth's integrity. This is observable in certain subsystems, for example in the atmosphere (global warming), in marine systems (overexploitation of fish stocks), or in soils (degradation). One crucial element of sustainability is the capacity of natural resources to sustain human demands. It is foreseeable that parts of the system are overburdened beyond their capacity. This holds likewise for waste disposal, as for the atmosphere (greenhouse gases) and the utilization of resources like ores and renewables like trees and fish. To sum up, one can state that the overexploitation of natural resources and economic growth causes environmental impacts which may lead several systems to the brink of collapse. In other words, humanity causes a multitude of problems and most of them are not grounded in one sector, region, either can they be described by one scientific discipline.

Thus, sustainability science is a discipline that can be placed as the one at the meeting point of different scientific disciplines. However, during the last four decades, science made remarkable progress in regard to an assessment on how climate and global change will affect livelihood conditions, and how humanity is accelerating the above mentioned changes. The question is how we can avoid certain human activities that destroy the functionality of certain subsystems of the Earth and how we can develop potential solutions. It is a major challenge to understand the dynamics of man-made environment systems as a basis for the development of sustainable transition pathways in the sense of planetary engineering and management. In other words, sustainability science addresses the man-made environment interface.

Although all these points have been well-known for decades, we need to ask why it is so difficult to achieve pathbreaking scientific results, which may help us to develop clear visions of real sustainable development. It is well-known that resource consumption is an accompanying factor of economic prosperity and global resource consumption is still steeply growing. In some countries we observe-mainly the advanced ones-that resource consumption stabilizes or

(C) 2013 by the authors; licensee Librello, Switzerland. This open access article was published under a Creative Commons Attribution License (http://creativecommons.org/licenses/by/3.0/).

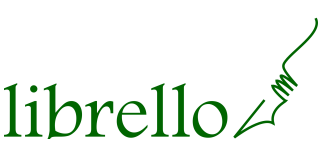


even decreases, while their high material intensity is still managed by exporting it to developing countries. Thus, the challenge to decouple resource consumption from economic development remains, and it is not only a question of a green economy, technological progress, or how natural resources are being utilized. It is indeed also a societal challenge. Human lifestyle changes might be a further catalyst for making headway towards sustainability. Nevertheless, current progress into this direction is slow, moreover, in large parts in the developing countries, we can see a tendency just to copy westernized lifestyles. A real innovation for the world would be a strategic approach for a sustainable economy that results in social equity and fairness, risk resilient livelihood conditions, sustainable resource use, and the avoidance of ecological scarcities-all these under consideration of planetary boundaries.

Nevertheless, sustainability is still an elusive concept. It is hard to define what sustainability really implies in terms of environmental constraints or societal development, in particular on a regional scale. Consequently, at the beginning of the 21st century, scientific bodies called for a more systematic sustainability science, e.g. International Council for Science defined sustainability as a major goal in its research strategies. Despite these efforts, concepts still lack real meaning. Thus, the aim should be to underpin activities dealing with the general aspects of sustainability with stronger and sounder scientific concepts. Questions, like: what exactly is sustainability? How can we achieve sustainability targets? And, what does 'being sustainable' mean? need to be in the foreground. Thus, sustainability science is environmental systems science.

Although all these points have been intensely discussed in recent decades, a thrilling and demanding journey still lies ahead for sustainability science. In regard to methodological terms, we need to encompass the different magnitudes of scales in terms of time, space and functions. Thus, sustainability science still invokes a lot of questions, i.e. we have to tackle, in particular, the following three challenges: 1) The provision of a methodological arsenal that allows the description and analysis of questions of sustainability in a comparable and transferable manner, i.e. we permanently have to ask ourselves what we can learn from singular cases in terms of the overarching sustainability challenge; 2) Options for solutions at different levels, e.g. regional and global, need to be assessed systematically in order to develop pathways which allow us to achieve predefined environmental targets, like the $2{ }^{\circ} \mathrm{C}$ target agreed in the Copenhagen Accord 2009; 3) As a lot of strategies are included under the term 'sustainability', there is a need to develop a concept which allows assessment and measurement of success of implemented sustainability measures.

However, sustainability itself is a challenge, because it needs ethical decisions from humankind itself whether we want to live in a safe environment or not. But how we achieve these safe limits is an issue of sustainability science, i.e. in terms of how to achieve these limits and what potential trade-offs there might be. The new journal Challenges in Sustainability provides a perfect platform for these goals. 